\title{
Learning English as Thai Adult Learners: An Insight into Experience in Using Learning Strategies
}

\author{
Kasma Suwanarak ${ }^{1}$ \\ ${ }^{1}$ Graduate School of Language and Communication (GSLC), the National Institute of Development \\ Administration (NIDA), Thailand \\ Correspondence: Kasma Suwanarak, Graduate School of Language and Communication (GSLC), the National \\ Institute of Development Administration (NIDA), 118 Serithai Road, Bangkapi, Bangkok 10240, Thailand \\ E-mail: kasma.suwanarak@gmail.com
}

Received: October 27, 2015 Accepted: November 22, 2015 Online Published: November 23, 2015

doi:10.5539/elt.v8n12p144 URL: http://dx.doi.org/10.5539/elt.v8n12p144

\begin{abstract}
This research aims to understand language learning strategies of Thai adult learners and factors affecting their strategy use. The participants are forty officers of General Service Division of the Council of State of Thailand, attending an English training course for developing their work potential. The data were collected through the questionnaire adapted from the Strategy Inventory for Language Learning (SILL). To further explore personal views about their experience in learning strategies and factors influential on their strategy use, fifteen participants were selected for individual interviews. Findings revealed that the learners reported an overall preference for the use of social strategies. Analysis of the qualitative data confirmed most of the SILL responses and revealed additional strategies and factors affecting the strategy use. Individual learners chose strategies suitable for the achievement of their goals and take account of their affective needs and work context. Overall, this study has emphasized the necessity of having qualitative data which can enrich and illuminate the findings of quantitative data and could be valuable resources for considering appropriate ways in which English proficiency of Thai adult learners could be developed. Implications are drawn regarding the language learning strategies of adult learners and their strategy use as professional engagement as well as recommendations for future research.
\end{abstract}

Keywords: adult education, adult learners, language learning strategies

\section{Introduction}

Research on second and foreign language learning strategies has revealed dynamic and fruitful development. Numerous studies (e.g., Bremner, 1999; Cohen \& Macaro, 2007; Green \& Oxford, 1995; Nyikos \& Oxford, 1993; Oxford, 1990; Vann \& Abraham, 1990; Wu, 2000; Yang, 1996) have put in both theory and teaching by showing productive results supporting the significant role of language learning strategies for effective and successful language learning. Factors related to language learning strategy use range from cultures and educational contexts to individual learner variables, such as gender, motivation, learning styles, years of learning, proficiency, and achievement. The majority of investigations have focused on young students and university learners, with very few studies exploring learning strategy use by full-fledged, mature students particularly in workplace (Intaraprasert, 2003; Peng, 2001; Suwanarak, 2013). These adult learners appear to have unique characteristics that are worth investigating.

Many studies of learning strategy use have been conducted, in a range of settings: secondary schools, tertiary institutions, within a target language community, or within a foreign language community. Few studies, though, have involved adult learners in the Thai context; the learning strategy of those who aim to be more proficient in English by regularly participating English training courses or even pursuing a higher degree in English for professional development. This study can be crucial as it could help support Oxford's (1990) taxonomy for language learning strategies (LLS) which constitutes an important framework to classify learning strategies of adult language learners such as those in this Thai context. The study could also contribute to the fields of Teaching English to Speakers of Other Languages (TESOL) and Adult Education by providing insights into how adult learners learn and use language learning strategies as professional engagement. Adult educators, in particular, could be aware of the adult learners' preferred learning strategies which have the potential to empower 
the learners to become more independent and cognizant of their learning behaviours. Consequently, appropriate training content and instructional methods could be developed and be supportive of enhancing adult learners' capabilities as individuals and work members.

Therefore, this study looks into the language learning strategies used by adult learners from differing linguistic backgrounds, aiming to improve their proficiency of English for their career prospects. The researcher, therefore, looks insight into their experience in using language learning strategies when learning English and particular factors influencing their use of learning strategies. In this regard, three research questions are developed based on the significance and purpose of this study:

1) What language learning strategies do the adult learners employ?

2) What insights about the experience in using language learning strategies do the adult learners reveal?

3) What factors are influential on the use of those English learning strategies?

\section{Review of Literature}

\subsection{Definitions of Language Learning Strategies}

Language learning strategies were generally defined as operations or techniques used by learners to facilitate their learning acquisition, store and recollect their language learning information (Chamot \& Küpper, 1989; Wenden \& Rubin, 1987; Nyikos \& Oxford, 1993). Regarding the concept of learning strategy, Stern (1992) gave a view that it is dependent on the assumption that learners take part in activities to achieve goals and learning strategies can be regarded as intended directions and learning techniques. A language classroom and a workplace are like problem-solving situations in which language learners have the opportunity to experience new input and difficult tasks given by their instructors, colleagues, customers, and others; consequently, it is inevitable that learners are challenged to find the best way to make use of language learning strategies.

\subsection{Background and Identification of Language Learning Strategies}

A large number of previous research studies on language learning strategies have been carried out since 1960 and have focused on subjects located in tertiary or secondary school classroom settings where English is learned as a foreign language to English-speaking communities. A smaller amount of research has investigated learners who are not in academic settings and are learning English for professional development. Nevertheless, numerous research studies on language learning strategies try to identify the strategies used by good learners through observations on second language learners in the classroom and also in more natural settings. For example, Rubin and Thompson (1994) suggested that "good" language learners be classified based on their personal characteristics, styles, and learning strategies. Primarily, good language learners are willing to learn and are accurate guessers. They tend to have strong drives to communicate or to learn language from communication. They are not often inhibit and are willing to be unreasonable, to make errors, to leave with a certain degree of ambiguity. Most of them usually focus on forms, practice and seek out opportunities to use the language. Besides, they tend to monitor their own language and others' as well as contemplate more on meanings.

\subsection{Classifications of Language Learning Strategies}

Many scholars in the area of language learning strategies have made good efforts in describing and classifying diverse learning strategies. Naiman et al. (1978), for example, categorized language learning strategies used by good language learners into five broad categories: a) an active task approach; b) realization of language as a system; c) realization of language as a means of communication and interaction; d) management of affective demands; and e) monitoring of second language performance.

Oxford (1990), a well-known theorist in language learning strategies, has widened one of the most extensively accepted classification taxonomies in the language learning area. Her model of language learning strategies consists of six subscales: memory, cognitive, compensation, metacognitive, affective, and social. Regardless of the content of this model and others, there is not absolute agreement on how many strategies there are; how language learning strategies should be defined, differentiated, and classified. For this study, the researcher considered that Oxford's Strategy Inventory for Language Learning (SILL) model has been used in a number of research studies. The SILL, therefore, will be used for exploring how the Thai adult learners experienced language learning strategies for their professional development.

\subsection{Factors Affecting Learners' Choices of Language Learning Strategies}

Research studies on language learning strategies have found that there are a number of factors supposed to have an effect on learners' choices of language learning strategies. Those include cultural background, language studied, stage of learning, age, motivation, language learning goals, ESL or EFL settings, language learning 
experience, language learning styles, gender, anxiety, lack of self-consciousness, and profession or academic specialty. For instance, Oxford and Ehrman (1993) suggested nine influencing factors affecting learners' choices of language learning strategies which consist of aptitude, motivation, anxiety, self-esteem, tolerance of ambiguity, risk-taking, language learning styles, age, and gender. Rubin and Thompson (1994) pointed out that learning strategies may vary with learning tasks, learning stages, age of learners, learning contexts, learning styles and cultural differences. To be more focused, Bialystok (2002) considered that factors affecting learners' choices of learning strategy use could be related to characteristics of learners (e.g., language learning aptitude, attitude, motivation, and personality variables) and characteristics of learning situations (e.g., time of exposure to the language and the teaching method employed).

In addition, from the studies on language learning strategies and other related studies, it is evident that learners' beliefs towards language learning influence the extent and type of strategy use in the language learning. Vann and Abraham and Vann (1990), for instance, suggested that learners have a belief of how a language is learned. That belief guides the learner's approach to language learning situations, the consequent strategy use, as well as the degree of accomplishment in language learning. Other factors such as age, educational background, intelligence and personality traits were also likely to be prominent in strategy use. This is also in line with what Suwanarak et al. (2013) found from the interviews with Thai graduate students about their language learning activities in and outside classroom. It was palpable that learners who believed in the importance of using the language reported greater use of communication strategies and attached mainly to meaning and social reasons.

\subsection{Previous Research on Language Learning Strategies of Adult Learners}

There are many investigations on language learning strategies of university students and adult learners in relation to their language performance, learning motivation, beliefs, and attitudes. Research on L2 learning strategies has indicated significant linkages between strategy use and language performance. According to the research, quantity and appropriateness of strategy use are associated with successful completion of language tasks and with higher overall language achievement and proficiency (Oxford, 1993).

In various studies, language performance levels have been based on the scores of standardised tests (Bremner, 1999), scores decided by teachers (Kiely, 2002), or self-ratings of individual learners (Wharton, 2000). Wu (2000) administered a translated Japanese version of the SILL (Oxford, 1990) and found that Taiwanese adult learners who were high-proficient in Japanese used more learning strategies and had greater frequency than less proficient learners did. From the study of EFL strategy use of 276 junior college students in Taiwan, Chen (2001) found that high-proficient learners showed a more frequent use of strategies than those who were low-proficient. In addition, compensation strategies were found to be the most frequently used and memory strategies were the least employed. In the Thai context, Intaraprasert (2003) conducted a quantitative study to look into the relationships between factors (English language ability levels, gender, field of study, and English language learning experiences) and language learning strategies of 488 Thai university students. The research findings showed that these language learners, on the whole, had medium frequency of use of out-of-class language learning strategies which varied significantly with reference to students' perceptions of English language ability levels.

Research shows that EFL strategy use is also related to learners' motivation, attitudes, and beliefs about language learning. Oxford and Ehrman (1995) carried out a study with 520 highly educated participants or adult learners on their strategy use. It was found that there was a strong relationship between language learning strategy use and persistence, motivation, and the ability to plan. Also, cognitive strategies were correlated with a wide range of affective and motivational variables. Another quantitative research on the relationship between EFL learning motivation and strategy use of 326 Chinese university students was carried out by Peng (2001). It was found that there were significant differences between the strategy use and each motivation aspect-motivational intensity, intrinsic motivation, extrinsic motivation, and requirement motivation. The students who had to study English according to the program of study requirement used language learning strategies less often and performed more poorly than students who were intrinsically motivated to learn English.

Yang (1996) investigated the strategy use of 68 Taiwanese university students by using a mixture of quantitative and qualitative methods. The data from an English Learning questionnaire, a slightly revised version of Oxford's SILL (1990), and group interviews indicated that the students were able to improve their use of learning strategies through awareness-raising in group interviews and informal strategy instruction. Similarly, the study of Liao (2000) on EFL learning motivation and strategy use was conducted by using multiple methods of questionnaires, semi-structured interviews, and classroom observation. Findings indicated that students lacked deep motivation to learn English and, when motivated at all, tended to be extrinsically motivated. Most of the 
students did not frequently report using a wide range of categories of EFL learning strategies. Students with low English-learning motivation were notably correlated with their little use of learning strategies.

The review of these studies provides the research empirical evidence in the field of language learning strategies that there is a dearth of knowledge about the relationships between learners' use of language learning strategies and any factors that determine those strategies, as stated in Cohen and Macaro (2007). The study focusing on the relationships between learners' uses of language learning strategies and any other related factors such as different professional groups as this study attempts is still needed.

\section{Research Methodology}

\subsection{Participants}

The participants of this study were forty Thai adult learners who were officers of a General Service Division of the Council of State of Thailand, attending an English training course for developing their work potential in response to the preparation for stepping towards the ASEAN community. Based on the pre-test and post-test scores as well as their performance in the training course, English proficiency of these adult learners could be roughly divided into three different levels: 1) high proficiency; 2) intermediate proficiency; and 3) low proficiency. The tests were adopted from the Test of English for International Communication (TOEIC) which is a standardized test administered by the Education Testing Service (ETS). The measure of the participants' proficiency level, therefore, was in relation to the TOEIC test scores. A large number of the adult learners $(n=23)$ appeared to be intermediate proficient, eleven of them showed low proficiency, and the other six were explicitly high proficient.

\subsection{Data Collection Methods}

This study obtained data through two data collection methods: a questionnaire and a semi-structured interview. The questionnaire was based on the Strategy Inventory for Language Learning or SILL model (Oxford, 1990); the strategy items were adapted and piloted to be fit the context of investigation. All the participants were requested to indicate their frequency of use of particular learning strategies by responding to 50 statements on the SILL questionnaire. Fifteen adult learners were then selected to have the semi-structured interview on the basis of their questionnaire responses and personal attributes. For good reasons, they proportionately drawn from three different levels of language proficiency; two were from high proficient level, eight were from intermediate proficient level, and five were from low proficient level.

\subsection{Data Analysis}

The quantitative data from the SILL were analysed in SPSS using traditional statistical procedures to find out the overall reported strategy use of the adult learners and their strategy use in terms of variables (age, genders and levels of English language proficiency). Correlations were examined between the four strategy subscales (MEM, COG, META and SOC) which remained after the analysis of reliability were carried out. Frequencies of responses in the three levels of proficiency for the SILL items were also described. Moreover, patterns of responses for the SILL items in relation to the four strategy scales and percentage of strategy use were revealed according to the three proficiency levels of the participants. Qualitative data from the interviews were content analysed by using interpretive analysis methods of topic ordering and constructing categories.

The description and analysis of the qualitative data could help ascertain the adult learners' responses to the SILL. Other information emerged from the qualitative data was the reported use of a number of strategies not included on the SILL.

\section{Findings and Discussion}

\subsection{Descriptive Analysis of the Quantitative Data}

Descriptive statistics of the SILL were examined to answer the first research question regarding learning strategy use of the adult learners. The responses of the adult learners were categorised into high, medium, and low use of language learning strategies based on their overall mean scores and frequency of strategy use. It was apparent that the adult learners had fairly frequent use; $77.5 \%$ reported medium to high usage.

Considering the mean scores and standard deviations of reported use of strategies at subscale level, it was found that the mean scores of SOC and META subscales were explicitly 'high', while those of COG and MEM subscales were considered 'medium' use of language learning strategies. Even though the context of this study was not an English speaking community, the rating of SOC strategies appeared the highest. To some extent, most of the adult learners in the context of this study considered that English was important for their working environment. They were well aware that they needed to use these strategies to improve their proficiency of 
English.

Regarding genders, T-test revealed no significant differences in the overall reported use of strategies at the subscale level between males $(n=16)$ and females $(n=24)$. However, certain trends in the use of learning strategies were evident after the adult learners were sub-divided into six age groups. It was interesting that the trend towards a preference for META strategies started from the age of 30 and the use of SOC strategies appeared typical for those who were in the 36-40 age group. There was no significant correlation between the variable of age and any SILL subscales. The strategies of the META and SOC subscales were rated higher than those of MEM and COG at all age levels. Apart from a slight preference for META strategies by the 30-34 age group, SOC strategies were rated the highest until 40 years of age. From that point onwards, META strategies were rated the utmost. Nevertheless, the difference between the age groups and the strategy use of the adult learners were not large. This could lead to the suggestion that the adult learners were remarkably similar in their use of strategies.

Based on their pre-test and post-test scores as well as their learning performances, the adult learners were be divided into three different levels: 1) high proficiency; 2) intermediate proficiency; and 3) low proficiency. A large number of the adult learners $(n=23)$ appeared to be intermediate proficient, eleven of them showed low proficiency, and the other six were explicitly high proficient. Replicated from the study of Green and Oxford (1995), significant variation across levels of proficiency was considered positive when variation occurred in a step-by-step pattern with an increasing use at higher levels of proficiency, negative when a step-by-step pattern showed a decreasing use of the strategy by higher levels of proficiency, or mixed when neither of these patterns was obvious.

There was no significant variation in overall strategy use between the three levels of English proficiency. The results of multivariate tests also proved no significant differences in the use made of the independent variables (MEM, COG, META, and SOC) by the three of different groups of language proficiency. It was interesting that five of the 50 SILL items from either MEM or COG subscales presented a positive variation. Of these five, one showed a positive variation whereas four indicated a mixed pattern of variation. There was a clear step-by-step pattern with an increasing use at higher levels of proficiency.

As shown in Figure 1, the pattern of response for Q15 "Write notes, messages, letters, or reports in English" showed a positive regular stair-step pattern. There were high responses across the three proficiency levels which were matched by decreasing low responses of the adult learners. The middle area of the bar chart indicated the percentage of the adult learners at each proficiency level reporting medium strategy use. It was apparent that adult learners with low proficiency in English were unable to make use of the Q15 strategy, but with gains in their English writing proficiency they reported making an increasing use of the strategy.

\section{Percentage of strategy use}

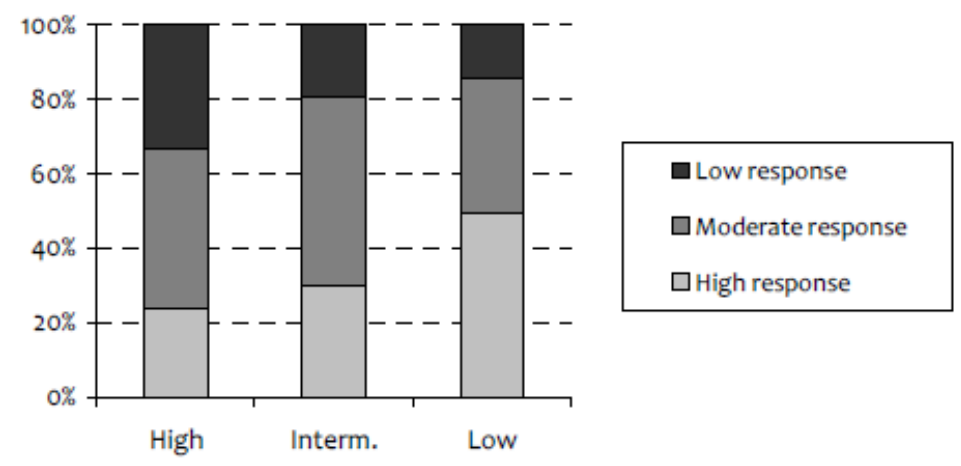

\section{Proficiency level}

Figure 1. Relationship of proficiency levels (Q15) 
The variation of four items $(\mathrm{Q} 1, \mathrm{Q} 2, \mathrm{Q} 10$, and Q11) was classified as mixed because none revealed the clear stair-step pattern outlined by Green and Oxford (1995). The pattern revealed by Q10 strategy "I read over the passage quickly then go back and read carefully" was rather different from the other three. For this item, there was no clear stair-step sequence across the three levels of proficient. However, as illustrated in Figure 2, increases in the reported high use of the strategy at all levels were matched by a related decrease in low responses.

\section{Percentage of strategy use}

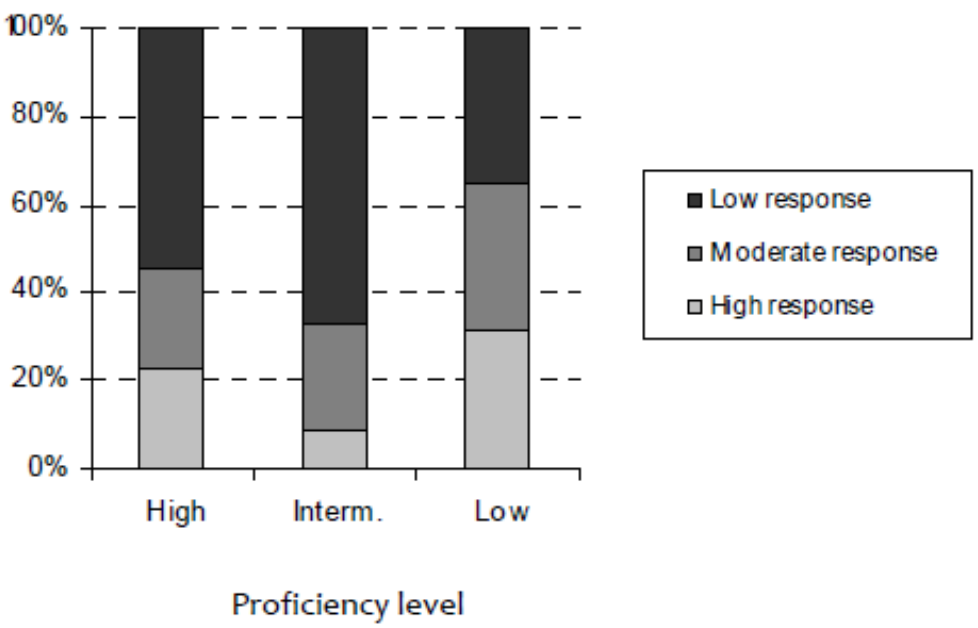

Figure 2. Relationship of proficiency levels (Q10)

At the low level of proficiency, $35 \%$ of the adult learners reported that they never or generally not using the Q10 item "I first read over the passage quickly then go back and read carefully." This indicates that the learners did not have the skimming reading skills. Quite the opposite, at the intermediate level of proficiency, reports of 'never' or 'generally not' had dropped to only a few, while reports of 'generally' or 'always' were made by a large number of the adult learners. This can be explained that by the intermediate level of proficiency the adult learners gained the skill of skimming and were aware of its use to be able to give response to the SILL. At the high level of proficiency, a 'generally' or 'always' response to this Q10 item fell to approximately half of the adult learners, implying that the skimming strategy was likely to become ordinary.

Other three items (Q1, Q2, and Q11) were also classified as mixed variation. There was slight difference between the percentages of 'never' or 'generally not' responses of high and intermediate proficiency levels for the Q1 item "I connect the sound of a new English word and an image or picture of the word to help me remember the word." In addition, there was only a very minor difference between the 'generally' or 'always' responses of intermediate and low proficient learners. By and large, as shown in Figure 3 below, the high proficient learners showed more use of the strategy than did others. 


\section{Percentage of strategy use}

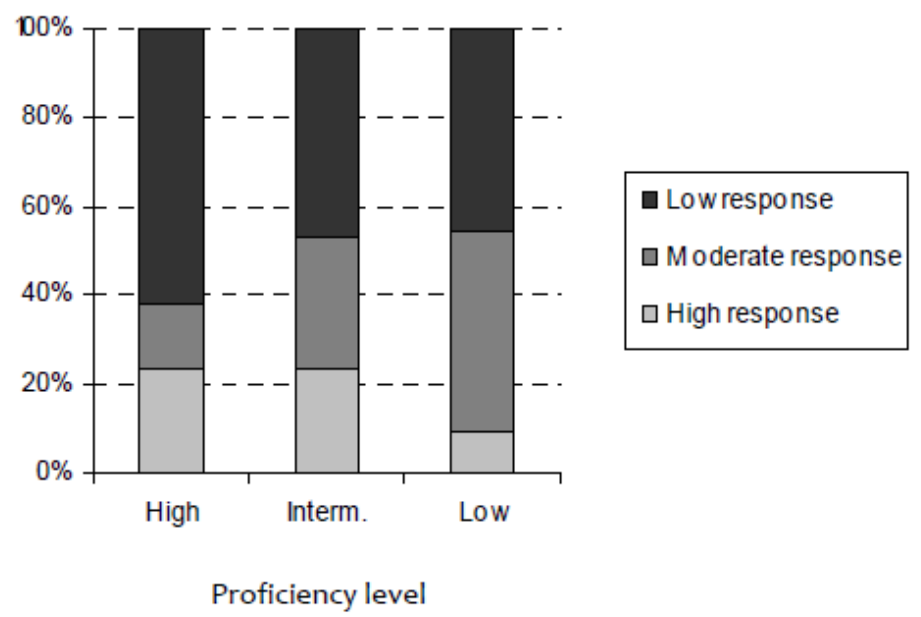

Figure 3. Relationship of proficiency levels (Q1)

The pattern of responses for Q2 "I use rhymes to remember new words" (see Figure 4) revealed that the adult learners used the strategy less as proficiency enhanced. The others who are more proficient, to some extent, come an increasing ability to utilize other resources.

\section{Percentage of strategy use}

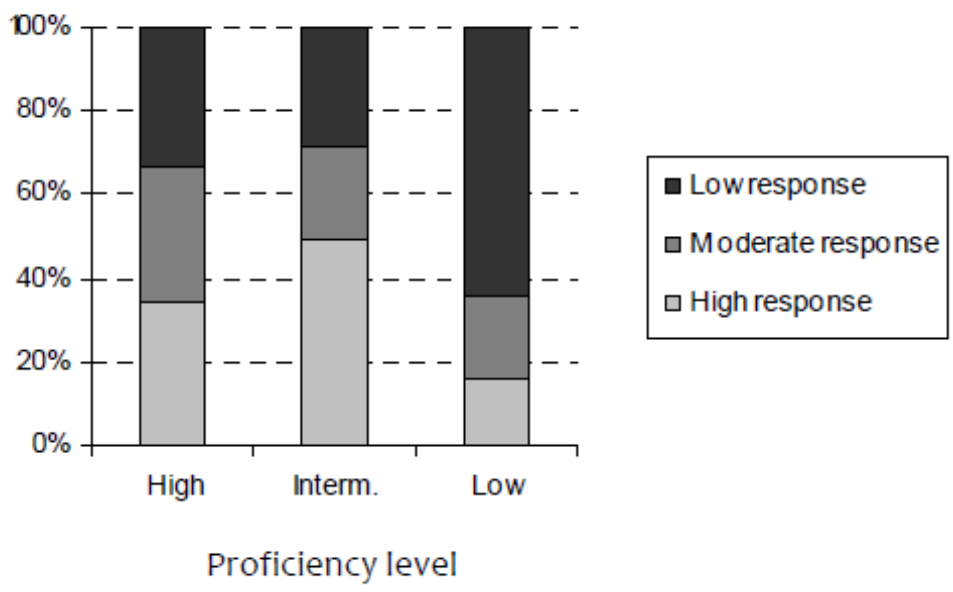

Figure 4. Relationship of proficiency levels (Q2)

As illustrated in Figure 5, the responses to Q11 "I try not to translate word-for-word" indicated that the high proficient adult learners reported making less use of the strategy than the intermediate proficient learners. It was interesting that the low proficient learners reported the least use of the strategy. This can be implied that the lack of English skills of these learners might have excluded them from employing such a translation strategy. 


\section{Percentage of strategy use}

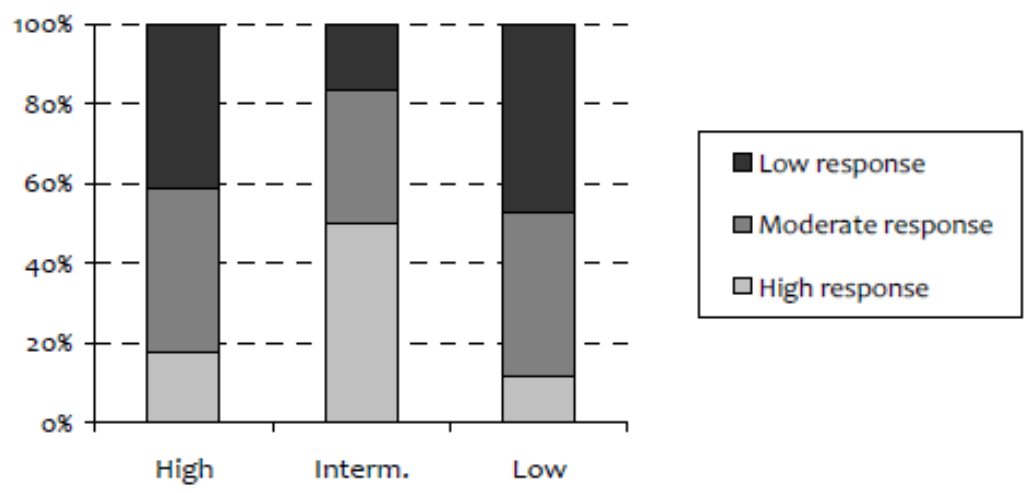

Proficiency level

Figure 5. Relationship of proficiency levels (Q11)

The number of individual items in this study which varied significantly in pattern of use by proficiency level was extremely low. However, the number of adult learners in this study $(\mathrm{N}=40)$ was much less than in the study of Green and Oxford $(\mathrm{N}=374)$ and the range of proficiency level was narrow, from zero proficiency to less than a functional level of English (1995). If the number of the adult learners was greater and the range of proficiency levels was wider, the scores of more SILL items would vary significantly across proficiency levels, possibly in a positive direction. Overall, the results obtained indicated that the adult learners in the context of this study had 'frequent' and 'moderate' use of a large number of strategies even though they were EFL learners in non-English speaking communities.

\subsection{Descriptive Analysis of the Qualitative Data}

From the interview, most of the adult learners (12 out of 15) reported in considerable details about the process they followed in learning new words. This was in accordance with the strategy item Q10 "I say or write new English words several times." There were a variety of uses which reflected the individuality of the adult learners in their use of the strategy. For instance, in some occasions, the learners referred to earlier learning situations as an influence on their current use of the strategy. Six of them revealed that other than the new English words learned in the classroom, the sources of new words were books, newspapers, televisions, the Internet and movies. As one of them [A8] said, "I heard the word 'probably' several times on TV, but I didn't know what it meant. I tried to write it down several times, but wasn't sure it was correct. Then I found it on the movie subtitle and could learn what it means." Many adult learners also indicated that they wrote new words down to facilitate their memory recall. One [A4] said, "I think it's easier for me to write the word down as it helps me to remember." Two others added that they kept new words in a note book which was their means of committing the word to memory. When asked whether or not they often practicing the pronunciation to themselves, they explained that it was just in case they were sure of the correct pronunciation.

Responses to the SILL revealed that the strategy item Q15 "I watch English language TV shows in English or go to movies spoken in English" was the highest rated Cognitive (COG) strategy (mean = 3.93). The interview data also revealed that 11 out of 15 considered this strategy use was important as both TV programs and movies appeared to be an accessible resource of English language learning. The findings do suggest that watching movies or TV programs in English may not be equally helpful for all learners at all times. Rather, certain programs may be pertinent and of greater interest to some learners. Some of the low proficient learners reported watching children's programs because the language used was clearly comprehensible. For some learners, particularly those who were high proficient, watching news broadcasts were important even if they did not always understand. For example, one [A11] said, "The news was very quick, but I love practicing my English this way. I don't understand much, but I could take some understanding what they're talking about through the picture." Another [A1] added, "Repetitions of news on some channels such as BBC and CNN or even Newsline 


\section{eventually enable me to understand."}

The views of most of the adult learners reported that they were making use of the strategy item Q38 "I think about my progress in learning English." All the learners showed a belief in positive progress in regard to their proficiency of English. During the interview, all the adult learners admitted that they needed more opportunities to use English at work and in daily basis. When asked to reflect on their current English language skills and to compare them with those had had before attending the English training course or having more practice of English skills, the learners could see general progress as well as on specific gains in listening, speaking, reading and writing. In most cases, before attending the training course, they had had little proficiency in any English language skills. For the time being, to some extent, they could see the subsequent progress they had made in English. For example, one of the intermediate proficient adult learners [A4] affirmed that he was able to act more confidently when interacting with native speakers of English at an international conference. Another [A9] who was once full of anxiety when first attended the training course of English revealed, "I think we need to have time to listen to someone. At the beginning I didn't recognize any words and my writing was terrible. It takes a while to start feeling better, maybe in the third course."

Some adult learners reflected on more specific aspects of their speaking skill, such as pronunciation, grammar, translating back into the first language and speaking on the phone. As one of them [A13] evaluated her progress in pronunciation, "I feel that it's better. What makes my speaking better is correct pronunciation that I've been trying to imitate the teacher and native speakers of English." Indeed, the adult learners clearly indicated the value of attending English classes to gain in the language proficiency. Without such improvement, they would have been less confident and dependent on others for their interaction and so would not have participated to the extent that career advancement entails.

\subsection{Additional Use of Language Learning Strategies}

The adult learners revealed that on occasions they made use of other language learning strategies which were not included on the SILL. Of all the additional strategies, the use of a dictionary was the most widely reported. Ten out of fifteen learners informed that they always took notes of the words they did not understand and looked up the meanings in a dictionary. This could be classified in a cognitive subscale which was not included on the SILL used in this study. Two adult learners addressed that they used a dictionary for checking meanings and pronunciation whereas five others reported that they use it for learning new vocabulary. Noticeably, they were intermediate to high proficient learners who tended to be able to make effective use of a dictionary in these ways. One of them [A3] revealed, "While watching a movie, I try to catch some words from the subtitle and translate what they speak by using a dictionary." In accordance with this, Wen and Johnson (1997) found dissimilarities in the use of a dictionary by high and low achievers. Before consulting a dictionary, high achievers assessed its usefulness while low achievers tended to use it rigidly. Thus, the findings suggest that using a dictionary be an important strategy in language learning, particularly somewhat for learners of English whose proficiency is not high. It is a strategy which could be helpfully exploited when learning English.

In line with a cognitive subscale, three adult learners indicated that the strategy of repetitive listening to a variety of sources - audio CDs for listening drills, movie soundtracks, songs, and video clips - helped improve their listening comprehension. For example, one of them [A9] described the way in which he extended his level of listening comprehension through songs. He narrated, "I just listen to radio programs in English. I enjoy listening to frequently repeated songs on the radio, starting from understanding nothing in the songs. Then, I gradually understand some words or perhaps sentences." Although these adult learners could see advantages of repetitive listening, the different ways in which they did so lay emphasis on their individuality. Thus, it could be concluded that the learners' choice of strategy use was consequent on their particular situation which was, in turn, explicit to the individual.

Three adult learners reported the use of this strategy which was in accordance with a compensation subscale. When not knowing how to put across something in English, they chose to use an avoidance strategy of keeping silent. Likewise, Bygate (1987) found that at times when unable to make productive use of English, students used the compensation strategy of keeping silent. Indeed, this strategy was reported during the interview with three adult learners. One of them [A15] remarked, "Every so often I don't know how to express in English, so I just keep quiet, think, and then speak to myself in Thai."Another [A10] emphasized that he avoided embarrassment when speaking English in front of others of the same first language or colleagues. He explained, "I wasn't confident to talk in front of others who know better English. I don't want to be embarrassed when being unable to maintain an active engagement in a real time conversation because of a lack of vocabulary. So, I choose to remain silent." 
In this regard, all the three revealed that planning time was important to their more effective production of English in a real speaking situation. This, to some extent, could help avoid using the strategy of keeping silent. One [A13] said, "I practice and write on the paper before talking on the phone. But it always turns to be very difficult for me when going to the meeting. Oh, I forget everything I've prepared for starting a conversation with foreigners. It is so terrible." In research on classroom tasks carried out by Foster and Skehan (1996), an effect for planning time on accuracy was found. Without planning time for speaking, it seemed that in situations when no planning time was possible, some learners chose to stay silent rather than engaging in an interaction where they risked the chance of communication breakdown and consequent awkwardness.

The preference of learners to work alone or with others could be considered a characteristic of a particular learning style. In accordance with a metacognitive subscale, the data obtained from the interview revealed that the adult learners held a conscious strategy when learning English. For example, one [A11] preferred to work with others for oral activities because that situation gave them the opportunity to improve her English.

Another gave a view that when information could be obtained, he preferred to work with others to share ideas. He [A4] remarked, "I like to work in a group so that I could compare my ideas with those of others." Alternatively, when the task demanded concentration or when the learners wanted to express their own views or feelings without being distracted by those of others, they preferred to work alone. One [A7] explained, "It depends on work you're doing and it depends on people you are around. And if I don't want my idea influenced by others, I prefer to be alone."

On the SILL, under a social subscale, there was no strategy item on receiving assistance of children and colleagues when learning English. However, during the interview, three adult learners revealed that they considered the strategy of receiving help with language learning from their children and colleagues. 'Help' could be regarded as any filling of a gap in English language knowledge, or correction of the adult learners' oral or written expression of English by another. Two of them revealed that they asked for help from their children who were studying in Grade 10 and 12 whereas another usually received help from her colleague who was working in the international affairs.

The two adult learners reported receiving unsolicited help from their children, which perhaps implied that both parents and children were comfortable with such a situation; children were happy to give help and parents were happy to receive it. As one of them [A4] illustrated, "My daughter is in grade 10 of a Thai-English bilingual school and I think her proficiency of English is great. I always seek help from her when watching a movie or even writing a report in English." Another [A5] revealed that his fifteen-year-old son who was an international school student could help with speaking; it was mainly the correction of pronunciation and vocabulary.

In general then, parents were happy to receive help from their children when learning English. It was not surprising that help with speaking came from a wide age range of children. Being an oral productive skill, the errors of speaking are overt, obvious to a proficient listener and their correction made quickly and without effort. Thus, children of all ages were able to give help, albeit simple or limited, to their parents. However, to the best of the researcher's knowledge, no research has been carried out on the role of children in the parent-learners' foreign language learning and on the attitude of the parent to that role. The finding of this part, therefore, could raise interesting questions for future research on this aspect.

\subsection{Factors Affecting the Use of Language Learning Strategies}

In response to the third research question of this study, the interview data revealed that the adult learners were active in their choices of language learning strategies and that their specific strategy use was consequences of various factors which could act dynamically and reciprocally on each other, depending on circumstances and the experiences which the learners brought to a particular situation.

The factors which were influential on the adult learners' use of strategy use were both intrinsic and extrinsic. Motivation and perceived value of the language learning activity, particularly in relation to their career prospects and the desire for greater satisfaction, feelings of competence, self-concept in terms of realistic awareness of strengths and weakness, attitudes to the English language, and confidence were considered internal factors influencing the adult learners' use of strategies. For external factors, significant others, such as teachers and colleagues, and learning environment to some extent had influence on the adult learners' use of learning strategies and learning success. Examples of the way in which these factors influenced the adult learners' strategies will be presented and discussed in the following sections.

It is apparent that the adult learners had the desire to become proficient in English so that they could attain their personal and professional goals. All the 15 adult learners participating in the interviews were well aware of the 
value of English language learning; they mentioned that having more chances for professional development and being able to fit in various English speaking situations constituted an important motivator to learn English. As one [A2] of them explained, "I need to be more proficient in English as it could help me more confident when interacting with foreigners and presenting my work in meetings, seminars and conferences in other countries. Oftentimes people try to talk with me and I can't understand." Another [A5] added "If I had better skills of English, I could obtain more opportunities in terms of my career advancement."

Noticeably, feelings of satisfaction and fulfillment show the progress that the adult learners were making towards their goals and this could be a great motivator for their further development. For example, one [A3] revealed "I feel that I'm accomplished when I could give better response to an English teacher. My post-test scores are also much higher. I think I become more confident and satisfied with my progress." The learner reported the use of self-encouragement strategy which made him feel better, function more effectively, and have greater confidence (Purpura, 1997).

On the other hand, anxiety could play an important role in language achievement (Brown, 2000). Although the adult learners did not directly report anxiety as an obstacle to their English language learning, most of them mentioned the negative feelings in relation to it. One [A12] of them illustrated "Most of the time I feel frustrated when trying to explain something in English. I don't know how to say. It's so embarrassing that I don't know how to explain what I am really expertise in my field in English." These feelings of frustration and embarrassment were developed from and worry the learners' inability to adequately express mature thoughts and ideas which in turn increase their anxiety level (Brown, ibid.). As a result, their motivation to learn the language could be decreased.

Implicitly, in response to the interview, most of the learners showed a sense of mastery or could apply knowledge and skills they possessed and learned. After attending English classes for a few months, the adult learners revealed that they had the benefit of hindsight and so were able to reflect on and report their developing skills in English. One of them [A7] explained "I think I become more proficient in writing and on the ways in which I could now apply the skills I had acquired to my work." It was also interesting that this confirmed the quantitative findings for Q17 "I write notes, messages, letter, or reports in English." This was apparent that when the proficiency levels of the learners was regarded, the learners recognized that they could make greater use of the strategy as their level of proficiency increased.

The factor of mastery was clearly evident in several adult learners at the stage of skill development after time had been spent for language learning. In accordance with this, a realistic awareness of strengths and weakness, or self-concept (Williams \& Burden, 1997), could also be operative. For instance, one [A11] disclosed that she was aware of her lack of comprehension in the work situation before she participated in the English training courses. In reflecting on their past weaknesses, some other learners could provide a realistic picture of their current strengths and weaknesses. One [A13] expresses "I always used present and past simple tenses. I never used a present perfect. But since I attended the training, I have realized that what the present perfect is for and I should try it." Thus, it was evident that the adult learners were aware of and able to report on their previous weakness in English and were also able to make realistic judgments about their proficiency in English.

According to Spolsky (2000), learning conditions refer to the social context where learning takes place. The social context plays an important role in developing in the learner a set of attitudes towards the target language. For the adult learners in the context of this study, it was very difficult to find opportunities to speak English in their daily lives. This lack of opportunities was perceived as obstacles to learning English. All the learners agreed that working in the government organization where there were a few number of native English speakers was disadvantageous to their language learning success. Many of them said that being surrounded by colleagues, friends, and family members who spoke Thai was not beneficial to their English language learning. One [A12] explained, "I spend most of my time with my work, my friends, and my family who don't speak English or which is not in English. If there were some American colleagues in my office, who knows, my English would be better."

Teachers could be considered as significant others that appeared influential to the learners' learning process and their use of language learning strategies. Six adult learners believed that teachers could play an important role of good facilitators for successful language learning. One [A15] said "I prefer learning English with the teacher who tries to put much effort in his/her students' learning and has more realistic expectations in terms of practical language use." This was in accordance with the fact that the adult learners taking part in the context of this study had maturity to understand their priorities and often had little patience with classes. They participated in the English training course because they wanted to develop their language proficiency through interesting activities. One [A9] described "I really appreciate the English teacher in this course. She is one of the best I've ever 
seen. She remembers everyone's name and always gives good supports for all students. The class is very dynamic. Time goes so fast; there are various kinds of fun activities and interesting role plays which can also be useful for real situations."

Overall, the adult learners revealed that they selected strategies based on the given learning conditions (both internal and external), such as social interaction, personal and professional goals, motivation, feelings, anxiety, and teachers. The main reasons to learn English, therefore, constitute the learning goals that would be achieved once the learners' choice of learning strategies could facilitate their learning.

\section{Conclusions}

The significance of the findings leads to the conclusion that the use of language learning strategies was individual to the adult learners. Individual learners chose strategies which, from their perspective, were suitable to the achievement of their goals and took account of their affective needs and work context. Specific strategies assumed a particular level of importance for individual adult learners. The findings of this study have contributed to the knowledge of strategy use of the Thai adult learners. In drawing on both quantitative and qualitative data, they have enhanced the understanding of language learning strategies. Of particular significance are the findings regarding factors affecting the use of language learning strategies. This brings to light an area in which further research could be particularly fruitful. It is believed that this study has made a valuable methodological contribution to the field of language teaching. The study has emphasized the necessity of having qualitative data which can enrich and illuminate the findings of quantitative data and, in consequence, greatly enhance the understanding of foreign language learners and the underlying broader processes of learning English as a foreign language.

\section{Implications}

This research has contributed to the knowledge base about learning behaviour of adult learners in the Thai context. The findings of this study show that the learning context plays an important role in language learning; however, the adult learners in the context of this study only socialized within the place where the Thai language is the mainly used. As a result, the learners have less opportunity to learn about the culture and consequently the pragmatics of the English language. Future research should focus on the exploration of the learning context and the acculturation processes of the adult learners in other similar settings.

Apparently, the findings of this study reveal that choices and use of language learning strategies are dependent on various internal and external factors; therefore, future research studies could put more emphasis on language acquisition of adult learners' by exploring how individual learners from different professions use language learning strategies. In addition, it is evident that there are some other language learning strategies which are not included in the SILL. Nevertheless, the non-SILL strategies are frequently used by a particular group of learners. Thus, the subsequent research studies should not be hastily drawn from the learners' responses on the SILL. Rather, the qualitative data should be considered to extend the findings of the SILL and to consolidate the data obtained from the quantitative findings. More qualitative research studies are, therefore, encouraged to be carried out in other similar contexts, focusing on the language learning strategy use in order to obtain more detailed information from the Thai adult learners' points of reference and experiences.

On the whole, for practical reasons, the need for future research in this field of language learning strategies is imperative as research and practice have shifted its focus to what the learner can do rather than on how teaching interventions can be more effective and what learning strategies teachers can initiate.

\section{References}

Bialystok, E. (2002). Cognitive processes of L2 users. In V. Cook (Ed.), Portrait of the L2 User (pp. 147-165). New York: Multilingual Matters.

Bremner, S. (1999). Language learning strategies and language proficiency: Investigating the relationship in Hong Kong. The Canadian Modern Language Review, 55(4), 490-514. http://dx.doi.org/10.3138/cmlr.55.4.490

Brown, H. D. (2000). Principles of Language Learning and Teaching (4th ed.). White Plains, NY: Longman.

Bygate, M. (1987). Speaking. Language Teaching - A scheme for teacher education. Oxford: Oxford University Press.

Chamot, A. U., \& Küpper, L. (1989). Learning strategies in foreign language instruction. Foreign Language Annals, 22(1), 13-24. http://dx.doi.org/10.1111/j.1944-9720.1989.tb03138.x

Chen, H. M. (2001). Language Learning Strategies Used by High and Low English Proficiency Students in a 
Technical College. Unpublished Thesis, National Changhua University of Education, Changhua, Taiwan.

Cohen, A. D., \& Macaro, E. (Eds.). (2007). Language Learner Strategies: Thirty years of research and practice. Oxford: Oxford University Press.

Foster, P., \& Skehan, P. (1996). The influence of planning and task type on second language performance. Studies in Second Language Acquisition, 18, 299-323. http://dx.doi.org/10.1017/S0272263100015047

Green, J. M., \& Oxford, R. (1995). A closer look at learner strategies, L2 proficiency, and gender. TESOL Quarterly, 29(2), 261-297. http://dx.doi.org/10.2307/3587625

Intaraprasert, C. (2003). EST Students and Classroom-Independent Strategies. Nakhon Ratchasima: Suranaree University of Technology.

Kiely, L. (2002). Learning Strategies for the Pilot Project for Modern Languages. Paper presented at the Annual Language Learning Conference, University of Limerick, Ireland.

Liao, Y. F. (2000). A Study of Taiwanese Junior High School Students' EFL Learning Motivation and Learning Strategies (Master's thesis). National Changhua University of Education, Taiwan.

Naiman, N., Frohlich, B., Stern, H., \& Todesco, A. (1978). The Good Language Learner. Toronto: Modern Language Center, Ontario Institute for Studies in Education.

Nyikos, M., \& Oxford, R. (1993). A factor analytic study of language learning strategy use: interpretations from information-processing theory and social psychology. The Modern Language Journal, 77(1), 11-22. http://dx.doi.org/10.1111/j.1540-4781.1993.tb01940.x

Oxford, R. L. (1990). Language Learning Strategies: What every teacher should know. New York: Newbury House/Harper \& Row.

Oxford, R. L. (1993). Research on second language learning strategies. Annual Review of Applied Linguistics, 13, 175-187.

Oxford, R. L., \& Ehrman, M. (1993). Second language research on individual differences. Annual Review of Applied Linguistics, 13, 188-205. http://dx.doi.org/10.1017/S0267190500002464

Peng, I. N. (2001). EFL Motivation and Strategy Use among Taiwanese Senior High School Learners (Master's thesis). National Taiwan Normal University, Taiwan.

Politzer, R. L. (1983). An exploratory study of self reported language learning behaviors and their relation to achievement. Studies in Second Language Acquisition, 6(1), 55-68. http://dx.doi.org/10.1017/S0272263100000292

Purpura, J. E. (1997). An analysis of the relationships between test takers' cognitive and metacognitive strategy use and second language test performance. Language Learning, 47, 289-325. http://dx.doi.org/10.1111/0023-8333.91997009

Rubin, J., \& Thompson, I. (1994). How to be a More Successful Language Learner (2nd Ed.). Boston: Heinle \& Heinle.

Spolsky, B. (2000). Language motivation revisited. Applied Linguistics, 21(2), 157-169. http://dx.doi.org/10.1093/applin/21.2.157

Stern, H. H. (1992). Issues and Options in Language Teaching. Oxford: OUP.

Suwanarak, K. (2013). Relationships among beliefs, learning strategies, and achievement in learning English of Thai graduate students in a public university. ABAC Journal, 33(1), 20-37.

Vann, R. J., \& Abraham, R. G. (1990). Strategies of unsuccessful language learners. TESOL Quarterly, 24(2), 177-198. http://dx.doi.org/10.2307/3586898

Wen, Q., \& Johnson, R. K. (1997). L2 learner variables and English achievement: a study of tertiary-level English majors in China. Applied Linguistics, 18(1), 27-48. http://dx.doi.org/10.1093/applin/18.1.27

Wenden, A., \& Rubin, J. (Eds.). (1987). Learner Strategies in Language Learning. Englewood Cliffs, NJ: Prentice-Hall. http://dx.doi.org/10.1111/j.1467-1770.1987.tb00585.x

Wharton, G. (2000). Language learning strategy use of bilingual foreign language learners in Singapore. Language Learning, 50(2), 203-43. http://dx.doi.org/10.1111/0023-8333.00117

Williams, M., \& Burden, R. L. (1997). Psychology for Language Teachers. Cambridge: Cambridge University Press. http://dx.doi.org/10.1177/0261927X970163001 
Wu, R. (2000). Exploring language learning strategies. Min-Chung Japanese Education Report, 3, 109-126.

Yang, N. D. (1996). Effectiveness awareness-raising in language learning strategy instruction. In R. Oxford (Ed.), Language learning strategies around the world: Cross-cultural perspectives (pp. 205-210). Honolulu: University of Hawai'i, Second Language Teaching \& Curriculum Center.

Zeynali, S. (2012). Exploring the gender effect on EFL learners' learning strategies. Theory and Practice in Language Studies, 2(8), 1614-1620.

\section{Copyrights}

Copyright for this article is retained by the author(s), with first publication rights granted to the journal.

This is an open-access article distributed under the terms and conditions of the Creative Commons Attribution license (http://creativecommons.org/licenses/by/3.0/). 